Article

\title{
A Full-Newton AC-DC Power Flow Methodology for HVDC Multi-Terminal Systems and Generic DC Network Representation
}

\author{
Leandro Almeida Vasconcelos ${ }^{1}{ }^{\mathbb{D}}$, João Alberto Passos Filho ${ }^{2, *(\mathbb{D}}$, André Luis Marques Marcato ${ }^{2}$ \\ and Giovani Santiago Junqueira ${ }^{3}$ \\ 1 Department of Electrical Engineering, Federal Institute of Northern Minas Gerais (IFNMG), \\ Montes Claros 39.400-149, Brazil; leandro.vasconcelos@engenharia.ufjf.br \\ 2 Department of Electrical Engineering, Federal University of Juiz de Fora (UFJF), \\ Juiz de Fora 36.036-900, Brazil; andre.marcato@ufff.edu.br \\ 3 Santo Antônio Energia, Santo Antônio Hydro Plant, Sao Paulo 05.477-000, Brazil; \\ giovanisjunqueira@gmail.com \\ * Correspondence: joao.passos@ufff.edu.br
}

Citation: Vasconcelos, L.A.;

Passos Filho, J.A.; Marcato, A.L.M.; Junqueira, G.S. A Full-Newton AC-DC Power Flow Methodology for HVDC Multi-Terminal Systems and Generic DC Network Representation. Energies 2021, 14, 1658.

https://doi.org/10.3390/en14061658

Academic Editor: Tomonobu Senjyu

Received: 20 February 2021

Accepted: 12 March 2021

Published: 17 March 2021

Publisher's Note: MDPI stays neutral with regard to jurisdictional claims in published maps and institutional affiliations.

Copyright: (c) 2021 by the authors. Licensee MDPI, Basel, Switzerland. This article is an open access article distributed under the terms and conditions of the Creative Commons Attribution (CC BY) license (https:// creativecommons.org/licenses/by/ $4.0 /)$.

\begin{abstract}
The use of Direct Current (DC) transmission links in power systems is increasing continuously. Thus, it is important to develop new techniques to model the inclusion of these devices in network analysis, in order to allow studies of the operation and expansion planning of large-scale electric power systems. In this context, the main objective of this paper is to present a new methodology for a simultaneous AC-DC power flow for a multi-terminal High Voltage Direct Current (HVDC) system with a generic representation of the DC network. The proposed methodology is based on a full Newton formulation for solving the AC-DC power flow problem. Equations representing the converters and steady-state control strategies are included in a power flow problem formulation, resulting in an expanded Jacobian matrix of the Newton method. Some results are presented based on HVDC test systems to confirm the effectiveness of the proposed approach.
\end{abstract}

Keywords: high-voltage direct current; multi-terminal HVDC systems; control modes on multiterminal HVDC system; power flow; Newton method

\section{Introduction}

With the prospect of the increasing use of Direct Current (DC) transmission links in power systems, it has become increasingly important to have techniques to model the devices responsible for the AC-DC interconnection in power system analysis software, particularly in the power flow (PF), to allow correct network modeling as a whole to improve the quality of simulation results that could be used in studies of operation and transmission expansion planning of electric power systems.

DC transmission has become an alternative that is technically and economically competitive in the transport of large amounts of active power over long distances, in underwater crossings with the use of cables, and in asynchronous connections within a large variety of lengths, including zero, between two areas [1-5].

The DC transmission links generally are characterized by the interconnection of two systems of Alternating Current (AC) by two converter stations: a rectifier and an inverter. The connection between these stations is established by one or more DC transmission lines: single or double polarity. The rectification and inversion are performed in the converter bridges composed by semiconductor elements.

High Voltage Direct Current (HVDC) transmission technology was used for the first time in Brazil in the 1980s to integrate the energy generated by the Itaipu Hydroelectric Power Plant, connecting the Foz do Iguaçu and Ibiúna converter stations, utilizing two 
dipoles at $\pm 600 \mathrm{kV}$, over about $800 \mathrm{~km}$. In 2009, Brazil resumed the use of HVDC transmission technology with the construction of the $\pm 600 \mathrm{kV}$ transmission system associated with the Rio Madeira hydroelectric complex (Santo Antônio and Jirau hydroelectric power plants), composed of two bipoles designed to transmit $6300 \mathrm{MW}$ over approximately $2400 \mathrm{~km}$, connecting Coletora Porto Velho and Araraquara stations. By the year 2020, an important initiative to consider is the establishment of the Belo Monte HVDC links (2539 km-long transmission), with the construction of the $\pm 800 \mathrm{kV}$ transmission system associated with the Belo Monte hydroelectric power plant.

From this context, it appears that the study of severe operating conditions is important to support studies on the reliability of hydroelectric plants. These studies can assist in assessing the Availability Factor (AFA) [6]. Thus, modeling the electrical system as close as possible to reality is of fundamental importance. This is the case of the Santo Antônio hydroelectric plant, which may be impacted by the behavior of the HVDC transmission system.

The power flow software is the most frequently used tool in both operation and expansion planning studies of electrical power systems. It is used to determine the equipment rating, electrical equipment loading and system losses, bus voltage magnitudes and angles, and reactive power support requirements to maintain voltages within limits for a given scenario and a contingency list. For each case study, the network configuration and parameters, the bus active and reactive load, and MW generation must be specified. The increasing complexity of power systems, introduced by new large-scale AC and HVDC interconnections and by the application of Flexible AC Transmission System (FACTS) devices in such systems, have imposed new challenges to power system engineers and software developers. The reference [7] describes a generic methodology for representing control devices and the associated challenges.

The commonly used techniques in studies of power flow alternate the convergence process between AC and DC system models. This method is carried out until the global convergence of the two systems is obtained. It is important to point out that the inclusion of DC links can cause, in general, a significantly slower convergence of power flow. One of the main reasons for this slow convergence is the different rates of convergence of the DC and $\mathrm{AC}$ systems, which interfere with each other, slowing system global convergence.

In reference [8], a simultaneous (full Newton) methodology for the representation of DC transmission links based on the DC transmission link of the hydro electrical unit Itaipu (Brazil) was proposed by including equations that model the converters, the DC network (considering only two DC bus), and control modes to the set of equations that model the power system. The proposed model aims to (i) improve the convergence characteristics of systems with coupling between the AC-DC set of equations in the Newton-Raphson method and (ii) allow the adjustment of the control modes automatically during the iterative process.

In [9], the authors present a versatile approach to AC/DC system representation, which is able to model several types of converter structures, including the conventional two-terminal AC-DC power flow, and to connect to more DC terminals. The sequential (alternate) method is used to solve the AC-DC power flow, in which the AC network solution is carried out through the conventional Newton-Raphson method, and in the DC network model, the system presents five variables per terminal. It is also proposed that the variation of taps be limited, which is an improvement compared to other methodologies. Another advantage is the possibility of solving DC systems connected in series by adjusting some equations of the DC network.

Another study of DC transmission links [10] uses the eliminated variable method, which is a simple and reliable tool for the study of DC transmission links in multi-terminal systems, in which the DC and AC variables are treated separately. In this work, the active and reactive powers demanded by inverters are treated as voltage-dependent loads. Thus, the DC steady-state equations are solved, and the DC variables are eliminated from the PF equations. Voltage-dependent PQ buses were adopted in [11] to represent the HVDC system in the power flow problem. The work [12] proposed a modified power flow 
formulation considering the HVDC system as a voltage-dependent load on the AC side at both DC system sides in two-terminal systems.

In [13], a nodal voltage-based universal steady-state PF formulation is proposed. The main goal is to consider the bipolar VSC-MTDC (Voltage Source Converter MultiTerminal HVDC). A power flow alternating iterative method is proposed to obtain the positive/negative-pole DC network power flow. A series of nodal equivalent methods involving various control strategies are also proposed for the power flow algorithm. A comparative study of full Newton and sequential AC-DC power flow formulations for a VSC-MTDC is presented in the paper [14].

In [15], the authors use a sequential methodology to present a study where the solution of the AC-DC power flow is intrinsically related to the characteristics of a linear coefficient matrix $G$, which integrates the information of the network and HVDC control modes. The main contribution of this paper is to demonstrate that a necessary condition to solve the HVDC system is that the coefficient matrix $G$ must be nonsingular. In the study, the conditions for the characteristic of a $G$ matrix under feasible combinations of control modes and the parameters of the HVDC systems are introduced. The reference [16] proposed an alternative approach also based on a sequential method for the AC-DC power flow solution to handle multi-infeed DC systems.

The authors of [17] present some methods based on the correlation analysis between the steady-state security region and operational constraints. The reference [18] proposes an operation strategy of the hybrid multi-terminal high voltage DC to increase the utilization of the AC transmission corridors in parallel with HVDC systems considering the available transmission capacity (ATC) between two electrical areas. An analysis of distribution networks is carried out in the reference [19]. This work proposed an integrated load flow approach for AC-DC distribution systems.

In this context, the main objective of this paper is to propose a new methodology for a full Newton AC-DC power flow formulation for an MTDC system with a generic methodology for representing the DC network in stationary studies. The main motivation is the increasing interest in the operational feasibility and potential application of multiterminal HVDC systems. It is sought to demonstrate that the proposed methodology provides an efficient and generic way to represent any DC network in HVDC multi-terminal systems through a system of equations. Finally, some results are presented based on HVDC test systems to validate the effectiveness and robustness of the proposed methodology.

From the above, the main contributions of this paper are

- to present an alternative power flow formulation based on a full Newton methodology for MTDC transmission systems, where all DC variables are considered in the formulation, allowing for a generic representation of HVDC control modes;

- to describe the AC/DC base transformation in the Jacobian matrix calculation;

- to propose a formulation that represents the generic DC network.

\section{Modeling Background}

The steady-state model for power flow studies of the HVDC utilized in this work is constituted by three subdivisions: the converter model itself, more specifically the rectifier and inverter model, the DC transmission line/network model, and the control system models for the Multi-Terminal HVDC (MTDC).

- converter model;

- DC transmission line/network model;

- control model in Multi-Terminal HVDC (MTDC) systems.

\subsection{Mathematical Model of the Converter}

The model for the converter used in Multi-Terminal HVDC systems can be conveniently represented by Figure 1. The variables are adequately represented in a p.u. system. 


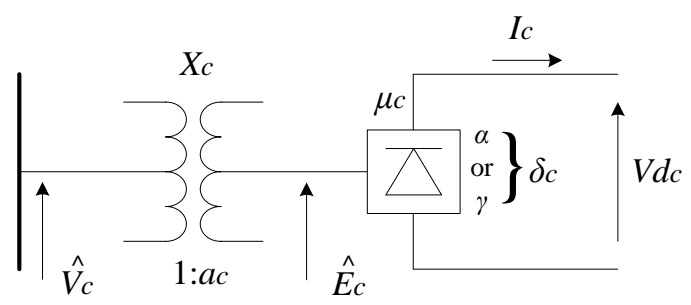

Figure 1. Converter model representation.

The values of rectifier and inverter commutation resistors, $R_{r}$ e $R_{i}$, are given by Equations (1) and (2). Note that $R_{i}$ is conveniently adopted as a negative value.

$$
\begin{aligned}
R_{r} & =\frac{3 \cdot X_{r}}{\pi} \\
R_{i} & =-\frac{3 \cdot X_{i}}{\pi}
\end{aligned}
$$

The representation of the rectifiers and inverters is based on the following premises [20]:

- $\quad$ the current $I_{\mathcal{C}}$ is ripple-free;

- the AC systems consist of constant-frequency, perfectly sinusoidal, balanced voltage sources behind balanced impedances, which assumes that all harmonic currents and voltages introduced by the commutation system do not propagate into the AC system because of filtering;

- the converter transformers do not saturate.

The equations that model the rectifier and inverter for MTDC systems are the same as those used in the DC link models for systems with only two DC terminals [8].

\subsubsection{Mathematical Model of the Rectifier}

The equations that model the behavior of the rectifier in the DC link are given by $[1,20,21]$ :

$$
\begin{gathered}
V d_{r}-k_{r} \cdot a_{r} \cdot V_{r} \cdot \cos (\alpha)+\frac{3}{\pi} \cdot X_{r} \cdot I_{r}=0 \\
\frac{2 \cdot \mu_{r}+\sin (2 \cdot \alpha)-\sin \left(2 \cdot\left(\alpha+\mu_{r}\right)\right)}{\cos (2 \cdot \alpha)-\cos \left(2 \cdot\left(\alpha+\mu_{r}\right)\right)}-\tan \left(\phi_{r}\right)=0 \\
\cos (\alpha)-\cos \left(\alpha+\mu_{r}\right)-\frac{2 \cdot R_{r} \cdot I_{r}}{k_{r} \cdot a_{r} \cdot V_{r}}=0
\end{gathered}
$$

\subsubsection{Mathematical Model of the Inverter}

Similarly, the equations that model the behavior of the inverter in the DC link are given by $[1,20,21]$ are

$$
\begin{gathered}
V d_{i}-k_{i} \cdot a_{i} \cdot V_{i} \cdot \cos (\gamma)-\frac{3}{\pi} \cdot X_{i} \cdot I_{i}=0 \\
\frac{2 \cdot \mu_{i}+\sin (2 \cdot \gamma)-\sin \left(2 \cdot\left(\gamma+\mu_{i}\right)\right)}{\cos (2 \cdot \gamma)-\cos \left(2 \cdot\left(\gamma+\mu_{i}\right)\right)}-\tan \left(\phi_{i}\right)=0 \\
\cos (\gamma)-\cos \left(\gamma+\mu_{i}\right)-\frac{2 \cdot R_{i} \cdot I_{i}}{k_{i} \cdot a_{i} \cdot V_{i}}=0
\end{gathered}
$$




\subsection{Transmission Network Model}

Considering a circuit that contains $N$ nodes with only independent current sources, the simplified nodal equations have the following form:

$$
\left[\begin{array}{c}
I_{1} \\
I_{2} \\
\vdots \\
I_{N-1}
\end{array}\right]=\left[\begin{array}{cccc}
G_{11} & -G_{12} & \cdots & -G_{1, N-1} \\
-G_{21} & G_{22} & \cdots & -G_{2, N-1} \\
\vdots & \vdots & \ddots & \vdots \\
-G_{N-1,1} & -G_{N-1,2} & \cdots & G_{N-1, N-1}
\end{array}\right]\left[\begin{array}{c}
V_{1} \\
V_{2} \\
\vdots \\
V_{N-1}
\end{array}\right]
$$

where $V_{1}$ and $V_{N-1}$ denote the voltages of $N-1$ nodes with respect to the reference node.

The proposed methodology provides an efficient and generic way to represent any DC network through the system of equations presented in (9). This approach has become useful in some studies, for example, in research related to "Tap HVDC", which seeks to disfigure the DC link as a transmission point-to-point system and make it flexible regarding the extraction or injection along the transmission line.

\subsection{Control Model in MTDC Systems}

The basic control principle for MTDC systems is a generalization of the one used in two-terminal systems [8]. As is shown in [20], the control characteristic for each converter is composed of piece-wise functions representing constant-current control (CC) and constantfiring angle control (Constant Extinction Angle (CEA) for inverters and Constant Ignition Angle (CIA) for rectifiers). In addition, an optimal constant-voltage segment may be included. The following is a general discussion of significant aspects related to the control of parallel-connected and series-connected systems.

The equations that model the controls are as follows:

- $\quad$ CIA/CEA Control with Constant-Voltage (CV):

$$
\begin{aligned}
\cos \left(\delta_{c}^{s c h}\right) & =\cos \left(\delta_{c}\right) \\
V d_{c}^{s c h} & =V d_{c}
\end{aligned}
$$

The use of the variable $\cos \left(\delta_{c}\right)$ instead of $\delta_{c}$ improves the linearity of the problem [9].

- Constant-Current Control (CC):

$$
\begin{gathered}
I_{c}^{s c h}=I_{c} \\
V d_{c}+0.97 \cdot\left(-k_{c} \cdot a_{c} \cdot V_{c} \cdot \cos \left(\delta_{c}^{\text {min }}\right)+R_{c} \cdot I_{c}\right)=0
\end{gathered}
$$

- Constant-Power Control (CP):

$$
\begin{gathered}
P_{c}^{c c^{s c h}}=P_{c}^{c c} \\
V d_{c}+0.97 \cdot\left(-k_{c} \cdot a_{c} \cdot V_{c} \cdot \cos \left(\delta_{c}^{\min }\right)+R_{c} \cdot I_{c}\right)=0
\end{gathered}
$$

where:

$$
k_{c}=\left(\frac{3 \sqrt{2}}{\pi}\right) \cdot n_{b}
$$

For the converter operating with current or power control mode, it is common to adjust the transformer tap control with the phase control. Consequently, the converter will operate at some DC voltage below its minimum extinction or ignition angle characteristic to prevent mode shifts from occurring with normal AC voltage changes. Typically, a $3 \%$ voltage margin is provided, with the normal $\alpha^{\mathrm{min}}$ or $\gamma^{\mathrm{min}}$ given in (13) and (15), and typical values of the control angles $\alpha$ and $\gamma$ are $15^{\circ}$ and $20^{\circ}$, respectively, for those DC terminals with a scheduled current or power control. From a practical point of view, this common voltage margin of $3 \%$ can be considered in the PF computation by adjusting the DC voltage equations for such converters with a coefficient of $0.97[9,22]$. 


\section{Proposed Methodology}

The proposed method of solution consists of including the equations that model the HVDC systems in the conventional power flow formulation. In order to achieve this goal, six new state variables will be included for each converter: $\phi_{c}, I_{c}, \mu_{c}, a_{c}, \delta_{c}$, and $V d_{c}$. The assumptions considered for Newton's method to solve simultaneously the AC-DC PF, based on the system of equations $\Delta y=J . \Delta x$, are presented below.

Considering the equations described in Section 2, the system of equations related to the HVDC system $(\Delta y)$ is structured as shown in Table 1.

Table 1. Mismatch vector of equations in AC-DC Power Flow $(\Delta y)$.

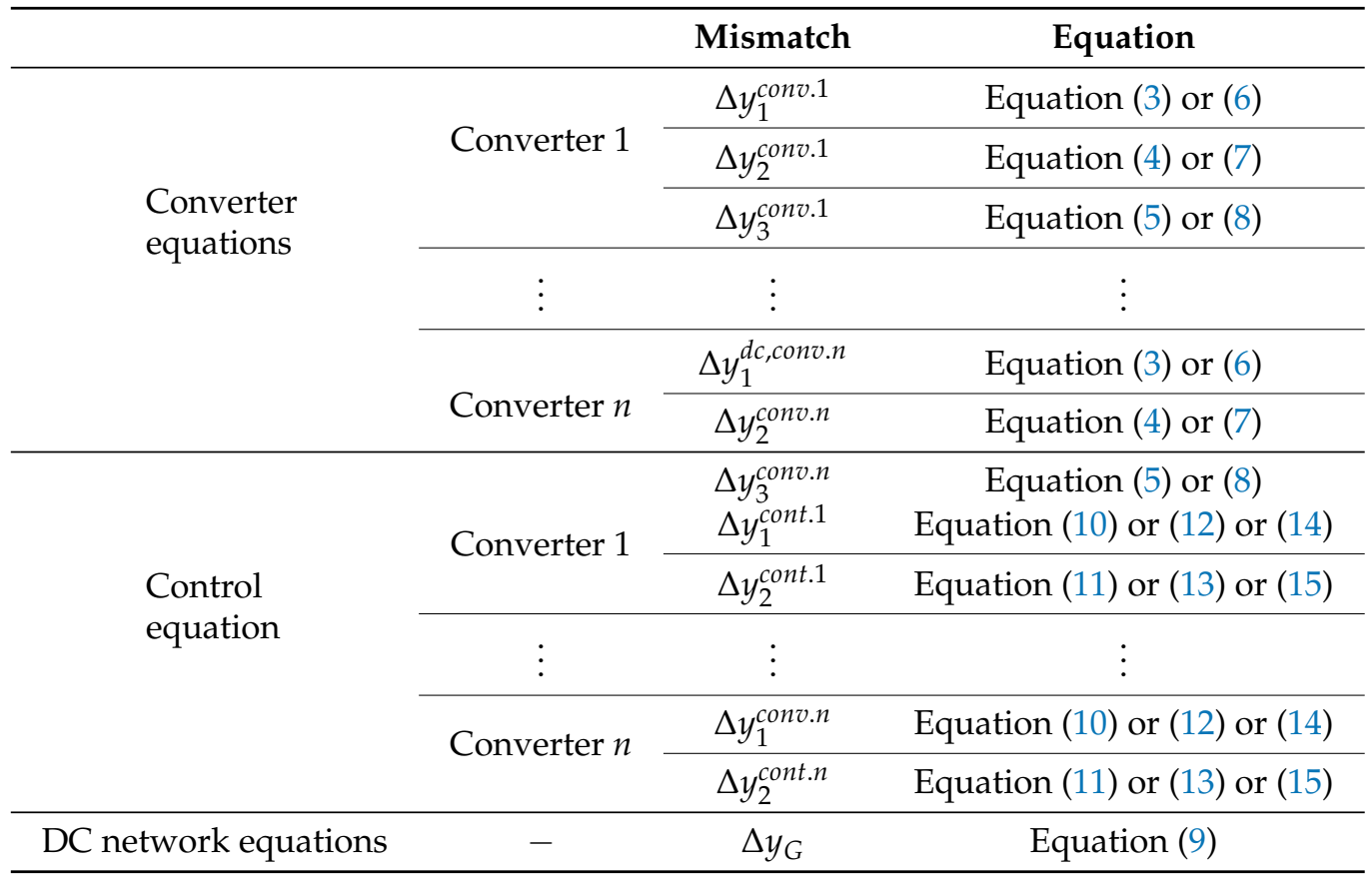

Based on Table 1, the vector of state variables related to the HVDC system $(\Delta x)$ will be updated according to the order presented in Table 2.

The general linear system to be solved at each iteration in the solution process is shown in Equation (16).

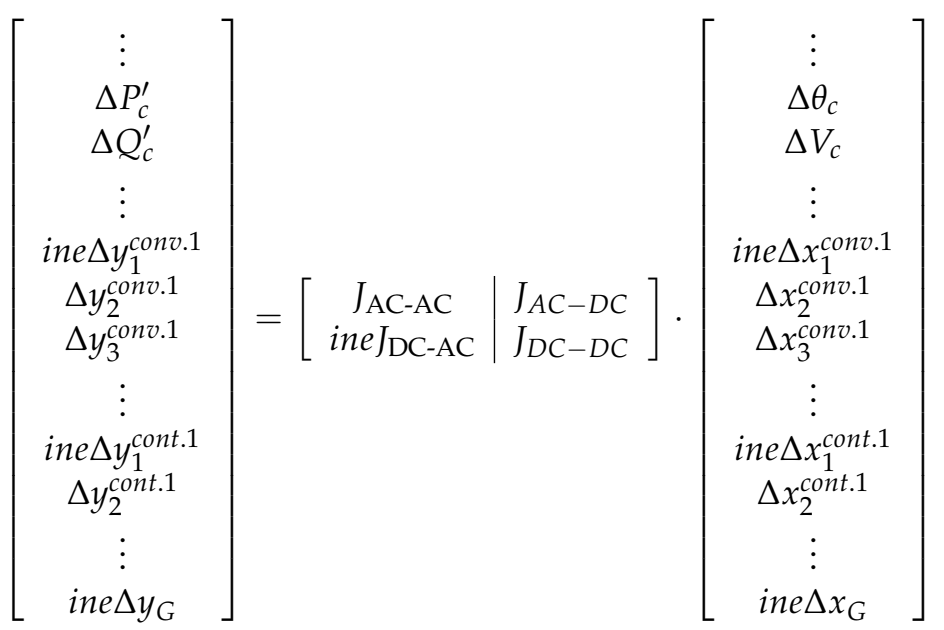


where:

$$
\begin{aligned}
& {\left[J_{\mathrm{AC}-\mathrm{AC}}\right]=\left[\begin{array}{cccc}
\ddots & \vdots & \vdots & \cdots \\
\cdots & \frac{\partial P_{c}^{\prime}}{\partial \theta_{c}^{\text {conv.1 }}} & \frac{\partial P_{c}^{\prime}}{\partial V_{c}^{\text {conv. } 1}} & \cdots \\
\cdots & \frac{\partial Q_{c}^{\prime}}{\partial \theta_{c}^{\text {conv.1 }}} & \frac{\partial Q_{c}^{\prime}}{\partial V_{c}^{\text {conv. } 1}} & \cdots \\
\cdots & \vdots & \vdots & \cdots
\end{array}\right]}
\end{aligned}
$$

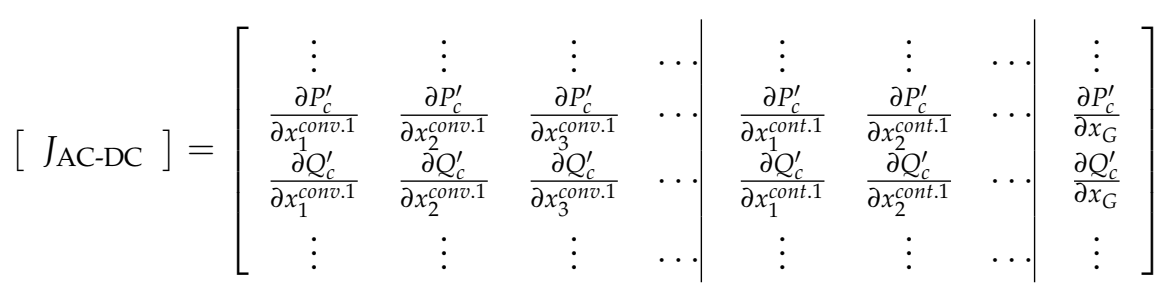

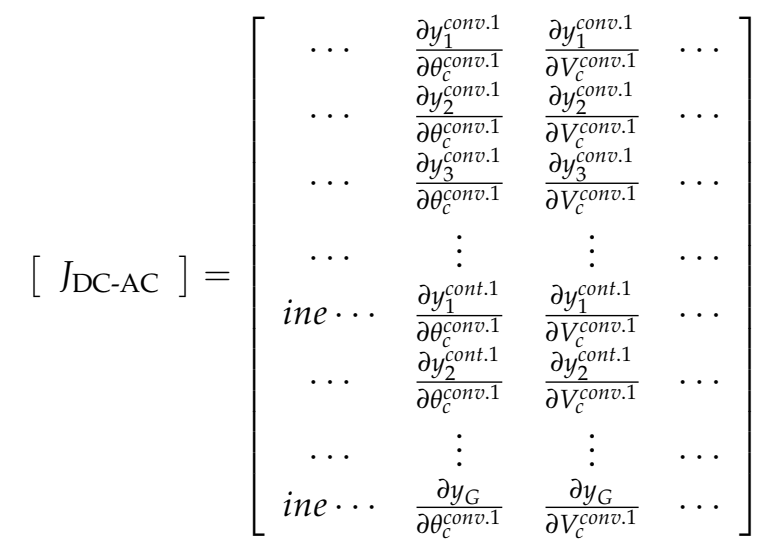

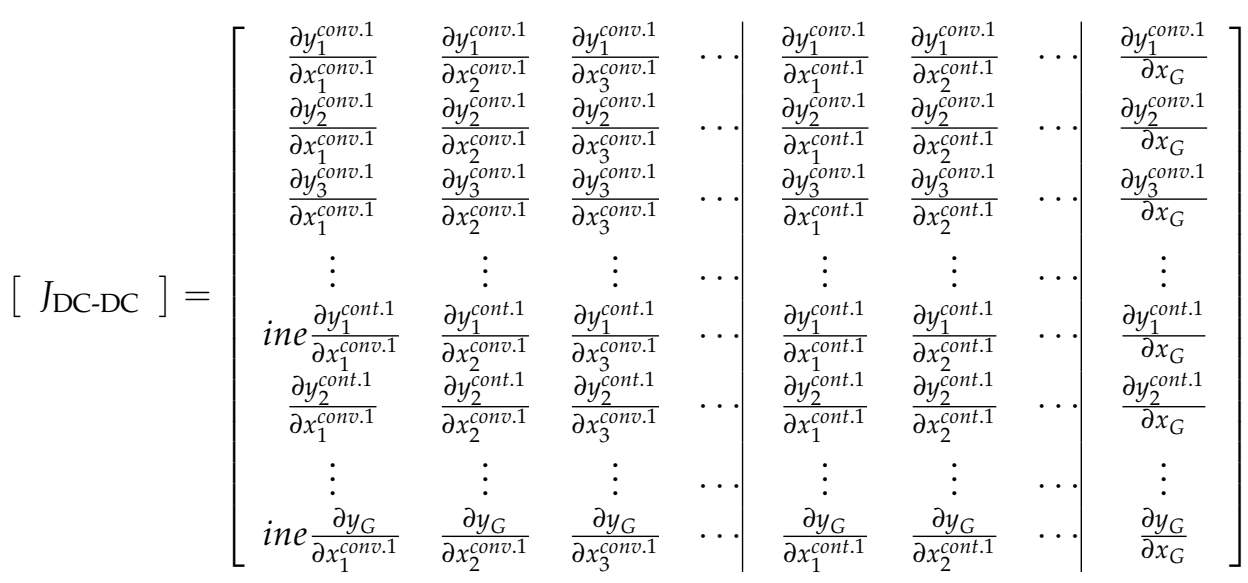


Table 2. Vector of state variables related to the High Voltage Direct Current (HVDC) system $(\Delta x)$.

\begin{tabular}{|c|c|c|c|}
\hline & & \multicolumn{2}{|c|}{$\Delta x$} \\
\hline \multirow{7}{*}{$\begin{array}{l}\text { State variables related to } \\
\text { the converter equations }\end{array}$} & \multirow{3}{*}{ Converter 1} & $\Delta x_{1}^{\text {conv. } 1}$ & $\Delta \phi_{c}^{\text {conv. } 1}$ \\
\hline & & $\Delta x_{2}^{\text {conv. } 1}$ & $\Delta I_{c}^{\text {conv. } 1}$ \\
\hline & & $\Delta x_{3}^{\text {conv.1 }}$ & $\Delta \mu_{c}^{\text {conv. } 1}$ \\
\hline & $\vdots$ & $\vdots$ & $\vdots$ \\
\hline & & $\Delta x_{1}^{\text {conv.n }}$ & $\Delta \phi_{c}^{\text {conv.n }}$ \\
\hline & Converter $n$ & $\Delta x_{2}^{\text {conv.n }}$ & $\Delta I_{c}^{\text {conv.n }}$ \\
\hline & & $\Delta x_{3}^{\text {conv.n }}$ & $\Delta \mu_{c}^{\text {conv.n }}$ \\
\hline \multirow{5}{*}{$\begin{array}{l}\text { State variables related to } \\
\text { the Control equations }\end{array}$} & \multirow{2}{*}{ Converter 1} & $\Delta x_{1}^{\text {cont. } 1}$ & $\Delta a_{c}^{\text {conv. } 1}$ \\
\hline & & $\Delta x_{2}^{\text {cont. } 1}$ & $\Delta \delta_{c}^{\text {conv. } 1}$ \\
\hline & : & $\vdots$ & $\vdots$ \\
\hline & \multirow{2}{*}{ Converter $n$} & $\Delta x_{1}^{\text {cont.n }}$ & $\Delta a_{c}^{\text {conv.n }}$ \\
\hline & & $\Delta x_{2}^{\text {cont.n }}$ & $\Delta \delta_{c}^{\text {conv.n }}$ \\
\hline \multirow{3}{*}{$\begin{array}{l}\text { State variables related to } \\
\text { the DC network equations }\end{array}$} & Converter 1 & \multirow{3}{*}{$\Delta x_{G}$} & $\Delta V d_{1}$ \\
\hline & $\vdots$ & & $\vdots$ \\
\hline & Converter $n$ & & $\Delta V d_{n}$ \\
\hline
\end{tabular}

By observing Equation (16), the original Jacobian matrix of the problem is preserved. The new derivatives are located in additional rows and columns. The AC-AC block is the original Jacobian matrix and contains the derivatives of the equations of MW and MVAr power from the AC system in relation to the variables of the original system state. In the AC interface buses, injections of active and reactive power regarding the DC system should be considered. These injections are given by [1]

$$
\begin{gathered}
P_{r}^{d c}=V d_{r} \cdot I_{r} \\
Q_{r}^{d c}=V d_{r} \cdot I_{r} \cdot \tan \left(\phi_{r}\right) \\
P_{i}^{d c}=V d_{i} \cdot I_{i} \\
Q_{i}^{d c}=-V d_{i} \cdot I_{i} \cdot \tan \left(\phi_{i}\right)
\end{gathered}
$$

From there, the residuals of the interface buses are given by

$$
\begin{gathered}
\Delta P_{c}^{\prime}=P_{c}^{s c h}-P_{c}^{\prime} \\
\Delta Q_{c}^{\prime}=Q_{c}^{s c h}-Q_{c}^{\prime}
\end{gathered}
$$

where:

$$
\begin{gathered}
P_{c}^{\prime}=P_{c a l c}+P_{c}^{d c} \cdot M V A_{a c}^{d c} \\
Q_{c}^{\prime}=Q_{c a l c}+Q_{c}^{d c} \cdot M V A_{a c}^{d c} \\
M V A_{a c}^{d c}=\frac{M V A_{\text {base }}^{d c}}{M V A_{b a s e}^{a c}}
\end{gathered}
$$

Tutorial Example

This tutorial example shows with more details the basic principles of the proposed AC-DC power flow with a HVDC multiterminal system with three converter terminals 
(connected to infinity buses), one intermediate DC bus (called $X$ in this example), and three HVDC lines, shown in Figure 2, which is composed of a DC network (represented by a generic methodology), with control modes that are shown below.

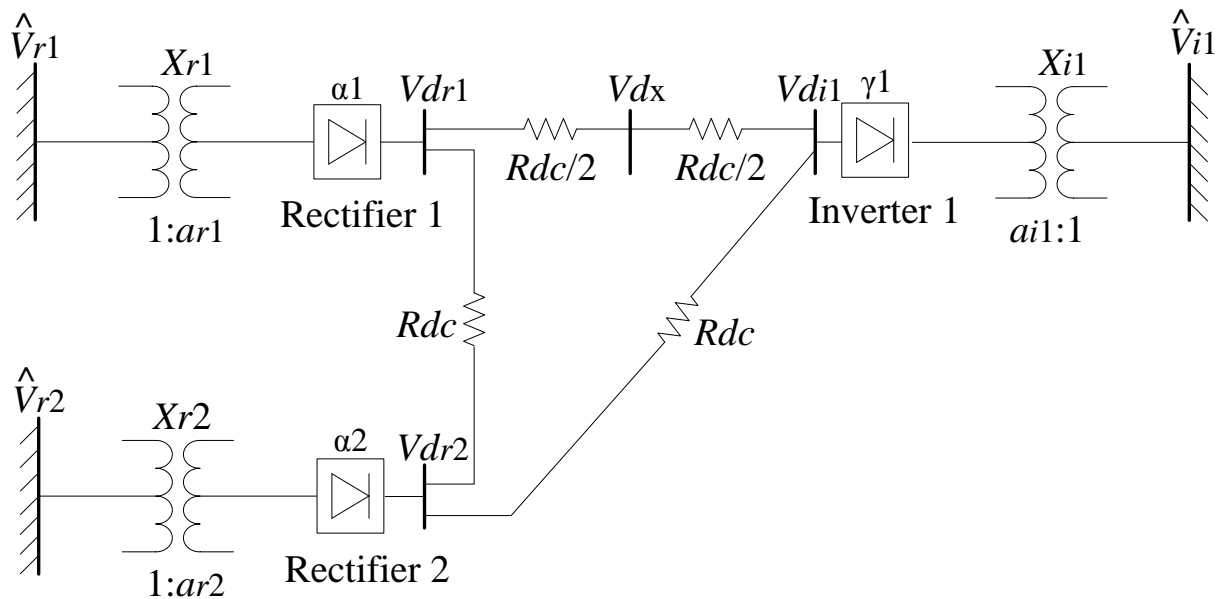

Figure 2. Tutorial Example: System test multiterminal HVDC.

For the case in study, the converters are working under the control modes shown in Table 3.

Table 3. Control mode configuration for the HVDC multi-terminal tutorial example test system.

\begin{tabular}{llll}
\hline & Rectifier 1 & Rectifier 2 & Inverter 1 \\
\hline Control modes & Constant-Power & Constant-Current & CEA \\
& $(\mathrm{CP})$ & $(\mathrm{CC})$ & $\begin{array}{l}\text { Constant-Voltage } \\
(\mathrm{CV})\end{array}$ \\
\hline
\end{tabular}

The system of equations that models, in a generic form, the DC network in this case is

$$
\left[\begin{array}{c}
I_{r 1} \\
I_{r 2} \\
I_{i 1} \\
I_{x}
\end{array}\right]=\left[\begin{array}{cccc}
\frac{3}{R_{d c}} & -\frac{1}{R_{d c}} & 0 & -\frac{2}{R_{d c}} \\
-\frac{1}{R_{d c}} & \frac{2}{R_{d c}} & -\frac{1}{R_{d c}} & 0 \\
0 & -\frac{1}{R_{d c}} & \frac{3}{R_{d c}} & -\frac{2}{R_{d c}} \\
-\frac{2}{R_{d c}} & 0 & -\frac{2}{R_{d c}} & \frac{4}{R_{d c}}
\end{array}\right] \cdot\left[\begin{array}{l}
V d_{r 1} \\
V d_{r 2} \\
V d_{i 1} \\
V d_{x}
\end{array}\right]
$$

The residuals equations related to the DC system $\left(\Delta y^{d c}\right)$ are

$$
\begin{gathered}
\Delta y_{1}^{d c}=-V d_{r 1}+k_{r} \cdot a_{r 1} \cdot V_{r 1} \cdot \cos \left(\alpha_{1}\right)-\frac{3}{\pi} \cdot X_{r 1} \cdot I_{r 1} \\
\Delta y_{2}^{d c}=-\frac{2 \cdot \mu_{r 1}+\sin \left(2 \cdot \alpha_{1}\right)-\sin \left(2 \cdot\left(\alpha_{1}+\mu_{r 1}\right)\right)}{\cos \left(2 \cdot \alpha_{1}\right)-\cos \left(2 \cdot\left(\alpha_{1}+\mu_{r 1}\right)\right)}+\tan \left(\phi_{r 1}\right) \\
\Delta y_{3}^{d c}=-\cos \left(\alpha_{1}\right)+\cos \left(\alpha_{1}+\mu_{r 1}\right)+\frac{2 \cdot R_{r 1} \cdot I_{r 1}}{k_{r} \cdot a_{r 1} \cdot V_{r 1}} \\
\Delta y_{4}^{d c}=-V d_{r 2}+k_{r} \cdot a_{r 2} \cdot V_{r 2} \cdot \cos \left(\alpha_{2}\right)-\frac{3}{\pi} \cdot X_{r 2} \cdot I_{r 2} \\
\Delta y_{5}^{d c}=-\frac{2 \cdot \mu_{r 2}+\sin \left(2 \cdot \alpha_{2}\right)-\sin \left(2 \cdot\left(\alpha_{2}+\mu_{r 2}\right)\right)}{\cos \left(2 \cdot \alpha_{2}\right)-\cos \left(2 \cdot\left(\alpha_{2}+\mu_{r 2}\right)\right)}+\tan \left(\phi_{r 2}\right)
\end{gathered}
$$




$$
\begin{gathered}
\Delta y_{6}^{d c}=-\cos \left(\alpha_{2}\right)+\cos \left(\alpha_{2}+\mu_{r 2}\right)+\frac{2 \cdot R_{r 2} \cdot I_{r 2}}{k_{r} \cdot a_{r 2} \cdot V_{r 2}} \\
\Delta y_{7}^{d c}=-V d_{i 1}+k_{i} \cdot a_{i 1} \cdot V_{i 1} \cdot \cos \left(\gamma_{1}\right)+\frac{3}{\pi} \cdot X_{i 1} \cdot I_{i 1} \\
\Delta y_{8}^{d c}=-\frac{2 \cdot \mu_{i 1}+\sin \left(2 \cdot \gamma_{1}\right)-\sin \left(2 \cdot\left(\gamma_{1}+\mu_{i 1}\right)\right)}{\cos \left(2 \cdot \gamma_{1}\right)-\cos \left(2 \cdot\left(\gamma_{1}+\mu_{i 1}\right)\right)}+\tan \left(\phi_{i 1}\right) \\
\Delta y_{9}^{d c}=-\cos \left(\gamma_{1}\right)+\cos \left(\gamma_{1}+\mu_{i 1}\right)+\frac{2 \cdot R_{i 1} \cdot I_{i 1}}{k_{i} \cdot a_{i 1} \cdot V_{i 1}} \\
\Delta y_{10}^{d c}=P_{r 1}^{d c s c h}-P_{r 1}^{d c} \\
\Delta y_{11}^{d c}=-V d_{r 1}+0.97 \cdot\left(k_{r 1} \cdot a_{r 1} \cdot V_{r 1} \cdot \cos \left(\alpha_{r 1}^{m i n}\right)-R_{r 1} \cdot I_{r 1}\right) \\
\Delta y_{10}^{d c}=I d_{r 2}^{d c} d_{11}^{s c h}-I d_{r 2}^{d c} \\
\Delta y_{12}^{d c}=-\cos \gamma_{i 1}^{s c h}-\cos \gamma_{i 1} \\
\Delta y_{13}^{d c}=V d_{i 1}^{d c} d_{r 2}+I d_{i 1}^{d c} \\
\Delta y_{14}^{d c}=I_{r 1}-\frac{\left(V d_{r 1}-V d_{r 2}\right)}{R_{d c}}-\frac{2 \cdot\left(V d_{r 1}-V d_{x}\right)}{R_{d c}} \\
\Delta y_{15}^{d c}=I_{r 2}-\frac{\left(V d_{r 2}-V d_{r 1}\right)}{R_{d c}}-\frac{\left(V d_{r 2}-V d_{i 1}\right)}{R_{d c}} \\
\Delta y_{16}^{d c}=I_{i 1}-\frac{\left(V d_{i 1}-V d_{r 2}\right)}{R_{d c}}-\frac{2 \cdot\left(V d_{i 1}-V d_{x}\right)}{R_{d c}} \\
\Delta y_{17}^{d c}=I_{x}-\frac{2 \cdot\left(V d_{x}-V d_{r 1}\right)}{R_{d c}}-\frac{2 \cdot\left(V d_{x}-V d_{i 1}\right)}{R_{d c}}
\end{gathered}
$$

The DC variables of the problem are included in the following order: $\phi_{r 1}, I_{r 1}, \mu_{r 1}, \phi_{r 2}$, $I_{r 2}, \mu_{r 2}, \phi_{i 1}, I_{i 1}, \mu_{i 1}, a_{r 1}, \alpha_{r 1}, a_{r 2}, \alpha_{r 2}, a_{i 1}, \gamma_{i 1}, V d_{r 1}, V d_{r 2}, V d_{i 1}$, and $V d_{x}$.

The solution of the general linear system of Equation (16) provides the values for the variables in the steady state of the AC/DC system.

\section{Results}

The proposed methodology is verified through the study of two test systems. The first one is a modified version of the IEEE 14-bus system, and the second one is a 4-bus test system considering three HVDC systems with different DC networks.

\subsection{Modified IEEE 14-Bus}

The first study is an AC-DC system with three terminals and two HVDC lines, shown in [15], based on the well-known IEEE 14-bus. The system topology is shown in Figure 3. The base power is 100 MVA. 


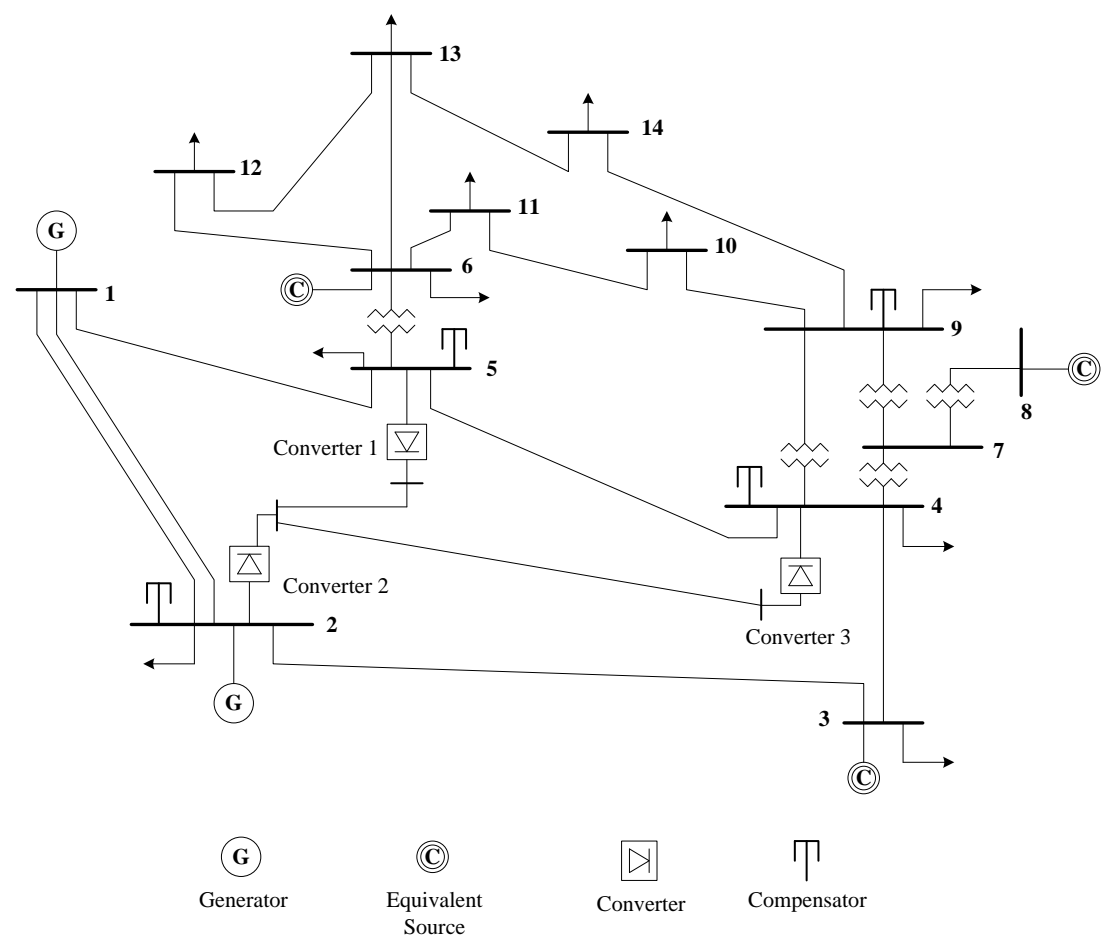

Figure 3. IEEE 14-bus test system with a radial three-converter HVDC multiterminal [15].

The parameters of the AC system are shown in Tables 4-8.

Table 4. Capacitor shunt compensation (MVAr).

\begin{tabular}{lllll}
\hline AC Bus No. & $\mathbf{9}$ & $\mathbf{2}$ & $\mathbf{4}$ & $\mathbf{5}$ \\
\hline Rated reactive power & 15.0 & 20.0 & 20.0 & 20.0 \\
\hline
\end{tabular}

Table 5. Reactance and tap of transformers (\%).

\begin{tabular}{llll}
\hline From Bus No. & To Bus No. & Ratio & $\boldsymbol{X}_{\boldsymbol{t}}$ \\
\hline 4 & 7 & 0.978 & 20.912 \\
4 & 9 & 0.969 & 55.618 \\
5 & 6 & 0.932 & 25.202 \\
\hline
\end{tabular}

Table 6. Generator Parameters.

\begin{tabular}{ccccc}
\hline Bus No. & $\begin{array}{c}\boldsymbol{V}_{\boldsymbol{g}} \\
(\boldsymbol{p} . \boldsymbol{u} .)\end{array}$ & $\begin{array}{c}\boldsymbol{Q}_{\max } \\
(\boldsymbol{M V A r})\end{array}$ & $\begin{array}{c}\boldsymbol{Q}_{\min } \\
(\boldsymbol{M V A r})\end{array}$ & $\begin{array}{c}\boldsymbol{P}_{\boldsymbol{g}} \\
(\boldsymbol{M W})\end{array}$ \\
\hline 1 & 1.060 & 150.00 & -150.00 & 232.38 \\
2 & 1.045 & 50.00 & -40.00 & 40.00 \\
3 & 1.010 & 40.00 & 0.00 & 0.00 \\
6 & 1.070 & 40.00 & -6.00 & 0.00 \\
8 & 1.090 & 40.00 & -6.00 & 0.00
\end{tabular}

$\overline{V_{g}}=$ generator terminal voltage; $Q_{\max }=$ maximum reactive power generation; $Q_{\max }=$ minimum reactive power generation; $P_{g}=$ output active power generation. 
Table 7. System load configuration.

\begin{tabular}{ccc}
\hline Load Bus No. & $\boldsymbol{P}_{\boldsymbol{l}(\boldsymbol{p} . \boldsymbol{u} .)}$ & $\boldsymbol{Q}_{\boldsymbol{l}(\boldsymbol{p} . \boldsymbol{u} .)}$ \\
\hline 2 & 0.217 & 0.127 \\
3 & 0.942 & 0.190 \\
4 & 0.478 & -0.039 \\
5 & 0.076 & 0.016 \\
6 & 0.112 & 0.075 \\
9 & 0.295 & 0.166 \\
10 & 0.090 & 0.058 \\
11 & 0.035 & 0.018 \\
12 & 0.061 & 0.016 \\
13 & 0.135 & 0.058 \\
14 & 0.149 & 0.050 \\
\hline
\end{tabular}

$P_{l}=$ active load power; $Q_{l}=$ reactive load power.

Table 8. Parameters of transmission lines and transformers.

\begin{tabular}{ccccc}
$\begin{array}{c}\text { From } \\
\text { Bus No. }\end{array}$ & $\begin{array}{c}\text { To } \\
\text { Bus No. }\end{array}$ & $\begin{array}{c}\boldsymbol{R} \\
\mathbf{( \% )}\end{array}$ & $\begin{array}{c}\boldsymbol{X} \\
\mathbf{( \% )}\end{array}$ & $\begin{array}{l}\boldsymbol{y} \\
\text { (MVAr) }\end{array}$ \\
\hline 1 & 2 & 1.938 & 5.917 & 5.28 \\
1 & 5 & 5.403 & 22.304 & 4.92 \\
2 & 3 & 4.699 & 19.797 & 1.38 \\
3 & 4 & 6.701 & 17.103 & 0.00 \\
4 & 5 & 1.335 & 4.211 & 0.00 \\
6 & 11 & 9.498 & 19.890 & 0.00 \\
6 & 12 & 12.291 & 25.581 & 0.00 \\
6 & 13 & 6.615 & 13.027 & 0.00 \\
7 & 8 & 0.000 & 17.615 & 0.00 \\
7 & 9 & 0.000 & 11.001 & 0.00 \\
9 & 14 & 12.711 & 27.038 & 0.00 \\
9 & 10 & 03.181 & 08.450 & 0.00 \\
10 & 11 & 8.205 & 19.207 & 0.00 \\
13 & 13 & 22.092 & 19.988 & 0.00 \\
\hline
\end{tabular}

$R=$ series resistance; $X=$ series reactance; $y=$ total shunt admittance.

The parameters of the HVDC system and the control modes in this study are shown in Tables 9 and 10, respectively.

Table 9. The HVDC system configuration.

\begin{tabular}{lllllll}
\hline $\begin{array}{l}\text { Converter } \\
\text { No. }\end{array}$ & AC Bus & $\boldsymbol{a}_{\boldsymbol{c}}$ (p.u.) & Type & $\boldsymbol{X}_{\boldsymbol{c}}$ (p.u.) & $\begin{array}{l}\text { HVDC } \\
\text { Line }\end{array}$ & $\boldsymbol{R}_{\boldsymbol{d}}$ (p.u.) \\
\hline 1 & 5 & 0.950 & Rect. & 0.083 & $1-2$ & 0.02 \\
2 & 2 & 0.975 & Rect. & 0.125 & $2-3$ & 0.02 \\
3 & 4 & 1.000 & Inv. & 0.125 & & \\
\hline
\end{tabular}

Table 10. Control modes configuration for Cases 1 and 2.

\begin{tabular}{lllllll}
\hline \multirow{2}{*}{ Converter No. } & Case $\mathbf{1}$ & \multicolumn{5}{c}{ Case $\mathbf{2}$} \\
\cline { 2 - 7 } & $\mathbf{1}$ & $\mathbf{2}$ & $\mathbf{3}$ & $\mathbf{1}$ & $\mathbf{2}$ & $\mathbf{3}$ \\
\hline Control mode & CP & CC & CEA & CIA & CP & CEA \\
Scheduled value & 0.47 & 0.47 & 17 & 14 & 0.56 & 17 \\
\hline
\end{tabular}

Using the proposed methodology, it is possible to solve the problem in both operating conditions. The results for Cases 1 and 2 are shown in Tables 11-14. It is important to point 
out that the proposed methodology converged in eight iterations in both cases. The adopted solution tolerances were $10^{-6}$ p.u. for the AC system and $10^{-9}$ p.u. for the DC system. All results were validated with the reference [15].

Table 11. AC bus voltage result.

\begin{tabular}{ccccc}
\hline \multirow{2}{*}{ Bus No. } & \multicolumn{2}{c}{ Case 1 } & \multicolumn{2}{c}{ Case 2 } \\
\cline { 2 - 5 } & Magnitude (p.u.) & Ang $\left(^{\circ}\right.$ ) & Magnitude (p.u.) & Ang $\left(^{\circ}\right.$ ) \\
\hline 1 & 1.0600 & 0.000 & 1.0600 & 0.000 \\
2 & 1.0450 & -4.084 & 1.0450 & -4.077 \\
3 & 1.0100 & -13.550 & 1.0100 & -13.561 \\
4 & 0.9940 & -12.189 & 0.9938 & -12.213 \\
5 & 0.9940 & -12.132 & 0.9937 & -12.162 \\
6 & 1.0700 & -17.380 & 1.0700 & -17.409 \\
7 & 1.0493 & -15.546 & 1.0492 & -15.571 \\
8 & 1.0900 & -15.546 & 1.0900 & -15.571 \\
9 & 1.0425 & -17.267 & 1.0425 & -17.293 \\
10 & 1.0400 & -17.570 & 1.0399 & -17.597 \\
11 & 1.0514 & -17.595 & 1.0514 & -17.623 \\
12 & 1.0541 & -18.188 & 1.0541 & -18.217 \\
13 & 1.0485 & -18.197 & 1.0485 & -18.226 \\
14 & 1.0270 & -18.687 & 1.0270 & -18.715 \\
\hline
\end{tabular}

Table 12. Active and reactive generation result.

\begin{tabular}{ccccc}
\hline \multirow{2}{*}{ Bus No. } & \multicolumn{2}{c}{ Case 1 } & \multicolumn{2}{c}{ Case 2 } \\
\cline { 2 - 5 } & $\mathbf{P}$ (MW) & Q (MVAr) & P (MW) & Q (MVAr) \\
\hline 1 & 233.1400 & 0.0028 & 233.1800 & 0.0044 \\
2 & 39.3671 & 41.7683 & 39.3652 & 41.3397 \\
3 & 0.0000 & 38.8600 & 0.0000 & 38.9700 \\
4 & 0.0000 & 0.0787 & 0.0000 & 0.0005 \\
5 & 0.0000 & 0.1516 & 0.0000 & 0.0388 \\
6 & 0.0000 & 30.3600 & 0.0000 & 30.5100 \\
8 & 0.0000 & 25.2000 & 0.0000 & 25.2600 \\
\hline
\end{tabular}

Table 13. HVDC system result for Case 1.

\begin{tabular}{cccc}
\hline \multirow{2}{*}{ Parameter } & \multicolumn{3}{c}{ Converter No.-Control Mode } \\
\cline { 2 - 4 } & $\mathbf{1 - C P}$ & 2-CC & 3-CEA \\
\hline$V d_{c}$ (p.u.) & 1.2069 & 1.1991 & 1.1819 \\
$\phi_{c}\left({ }^{\circ}\right)$ & 18.7800 & 29.2480 & 27.8680 \\
$I_{c}(p . u)$. & 0.3894 & 0.4700 & -0.8594 \\
$\delta_{c}\left({ }^{\circ}\right)$ & 14.0600 & 24.1800 & 17.0000 \\
$\mu_{c}\left({ }^{\circ}\right)$ & 8.7690 & 9.6480 & 19.5290 \\
$a_{c}(p . u)$. & 0.9500 & 0.9750 & 1.0000 \\
$P_{c}^{d c}(M W)$ & 46.9967 & 56.3571 & -101.5734 \\
$Q_{c}^{d c}(M V A r)$ & 15.9810 & 31.5594 & 53.7087 \\
\hline
\end{tabular}

The comparison of Tables 10 and 13 shows that the proposed methodology was effective in controlling the scheduled values in Case 1 considering the CP, CC, and CEA modes, respectively.

Regarding Case 2, the comparison of Tables 10 and 14 also shows that the proposed methodology was effective in controlling the scheduled values considering the CIA, CP, and CEA modes, respectively. 
Table 14. HVDC system result for Case 2.

\begin{tabular}{cccc}
\hline \multirow{2}{*}{ Parameter } & \multicolumn{3}{c}{ Converter No.-Control Mode } \\
\cline { 2 - 4 } & 1-CIA & 2-CP & 3-CEA \\
\hline$V d_{c}(p . u)$. & 1.2069 & 1.1990 & 1.1818 \\
$\phi_{c}\left({ }^{\circ}\right)$ & 18.7740 & 29.2620 & 27.8770 \\
$I_{c}(p . u)$. & 0.3932 & 0.4671 & -0.8603 \\
$\delta_{c}\left({ }^{\circ}\right)$ & 14.0000 & 24.2300 & 17.0000 \\
$\mu_{c}\left({ }^{\circ}\right)$ & 8.8620 & 9.5820 & 19.5440 \\
$a_{c}(p . u)$. & 0.9500 & 0.9750 & 1.0000 \\
$P_{c}^{d c}(M W)$ & 47.4562 & 56.0053 & -101.6720 \\
$Q_{c}^{d c}(M V A r)$ & 16.1312 & 31.3798 & 53.7806 \\
\hline
\end{tabular}

\subsection{Four-Bus Test System}

Figure 4 shows the topology of the four-bus test system. This system consists of three parallel HVDC systems, each of them with a different DC network configuration. However, it is important to point out that the three DC networks are equivalent. Therefore, the main objective here is to demonstrate that the proposed methodology is generic, allowing the calculation of voltage and current in any internal DC bus or circuit.

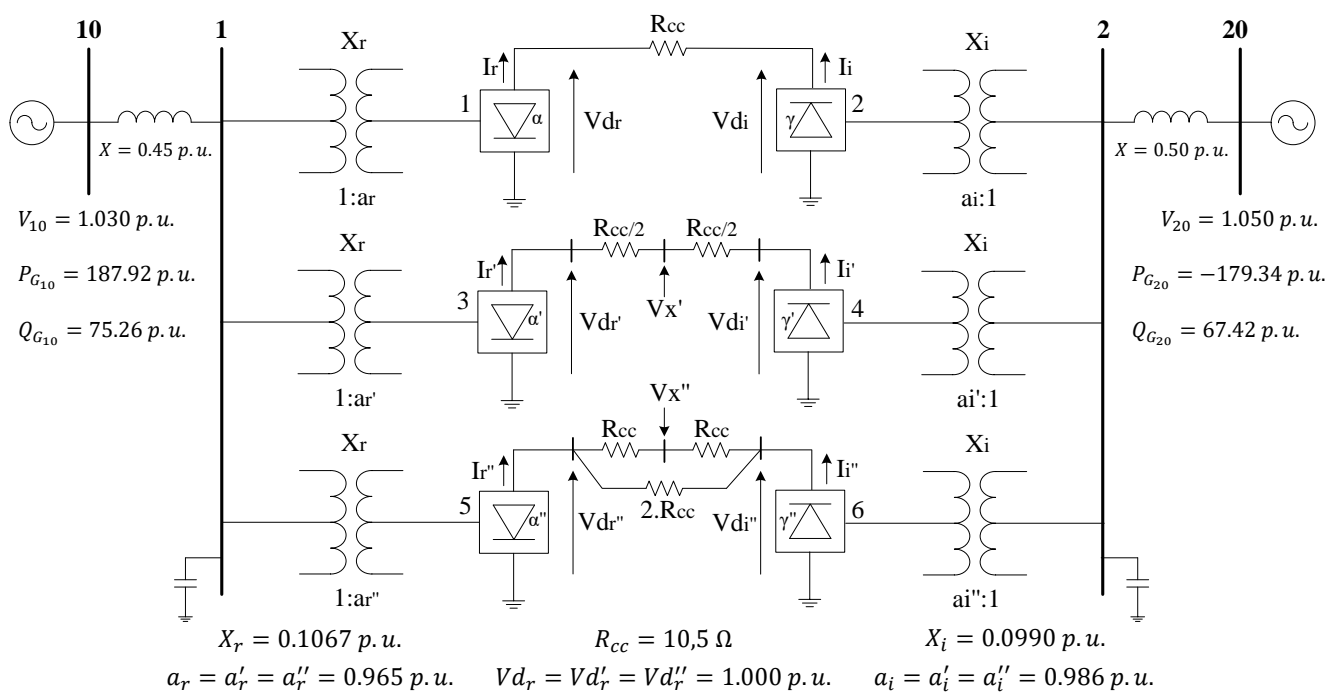

Figure 4. Four-bus test system including three HVDC with different DC networks.

The proposed power flow converged in four iterations. The converged DC voltages in the intermediate bus are $V_{x}^{\prime}=V_{x}^{\prime \prime}=0.9772 p . u$. The DC voltages in the inverter are $V d_{i}=V d_{i}^{\prime}=V d_{i}^{\prime \prime}=0.954$ p.u., and the currents are proportional to the circuit resistance. Moreover, it is important to highlight that the rectifier and inverter solutions in each HVDC are the same, as expected. This result shows that the proposed methodology is capable of solving a generic DC network.

A similar test was carried out using a large-scale system corresponding to a heavy load condition of the Brazilian Interconnected System topology for August 2018. This system comprises 6520 buses and 9487 circuits with a total active power demand of 81,865.4 MW and a reactive power demand of 20,383.7 MVAr. The results were consistent with those presented for the four-bus test system.

\subsection{Discussion}

The results obtained by the proposed methodology demonstrate the efficiency and the robustness of the tool for the simultaneous solution of the AC-DC power flow for analyzing 
MTDC systems. The proposed methodology uses the simultaneous strategy for the AC-DC power flow solution. This choice is related mainly to the following factors. First, because of the work proposed in [8], in which an analysis for the simultaneous solution of AC-DC power flow for steady-state studies is developed, for a DC system of only two terminals, based on the DC transmission link of Itaipu, which has served as the premise for the studies proposed in this paper. Second, the full Newton methodology is a well-established tool in the general literature on the subject, and, depending on the system feature, the choice of a sequential strategy could result in a delay in the AC convergence process, so the simultaneous strategy might be more interesting in these scenarios. Third, for the purposes of the study, the chosen method is best suited to the needs of this work. Finally, another decisive factor in this choice is related to the fact that there are few studies nowadays about the solution of Multi-Terminals HVDC systems using the simultaneous strategy.

\section{Conclusions}

This paper addresses the main assumptions involved in the modeling of MultiTerminal HVDC systems in the AC-DC power flow problem for steady-state studies. The proposed methodology is based on a full Newton formulation of the AC-DC power flow problem for a multi-terminal HVDC system with a generic methodology for representing the DC network in steady-state studies.

The results show that the proposed methodology is valid and effective in power transmission studies via Multi-Terminal HVDC systems. It can be stated that the methodology and the proposed models constitute valuable tools in solving current problems of AC-DC power flow, as a result of the increase in electricity demand, the interconnection of systems operating in different frequencies, and a more intensive use of Multi-Terminal HVDC transmission structures in electric power systems.

Author Contributions: Conceptualization, L.A.V. and J.A.P.F.; methodology, L.A.V. and J.A.P.F.; software, L.A.V.; validation, L.A.V. and J.A.P.F.; formal analysis, L.A.V. and J.A.P.F.; investigation, L.A.V. and J.A.P.F.; resources, L.A.V. and J.A.P.F; data curation, L.A.V. and J.A.P.F.; writing-original draft preparation, L.A.V. and J.A.P.F.; writing-review and editing, L.A.V., J.A.P.F. and A.L.M.M.; visualization, L.A.V., J.A.P.F. and A.L.M.M.; supervision, A.L.M.M. and J.A.P.F.; project administration, A.L.M.M. and G.S.J.; funding acquisition, G.S.J. All authors have read and agreed to the published version of the manuscript.

Funding: This paper is the result of a partnership between Santo Antônio Energia and the Federal University of Juiz de Fora (UFJF) as well as received financial support from ANEEL's R\&D - Electric Sector (CT.PD.318.2019).

Institutional Review Board Statement: Not applicable.

Informed Consent Statement: Not applicable.

Data Availability Statement: Not applicable.

Acknowledgments: The authors would like to thank Santo Antônio Energia, the National Research Council (CNPq), the Brazilian Federal Agency for Support and Evaluation of Graduate Education (CAPES), and the State of Minas Gerais Research Foundation (FAPEMIG) for the financial support through INERGE (National Institute of Science and Technology in of Electric Energy).

Conflicts of Interest: The authors declare no conflict of interest. 


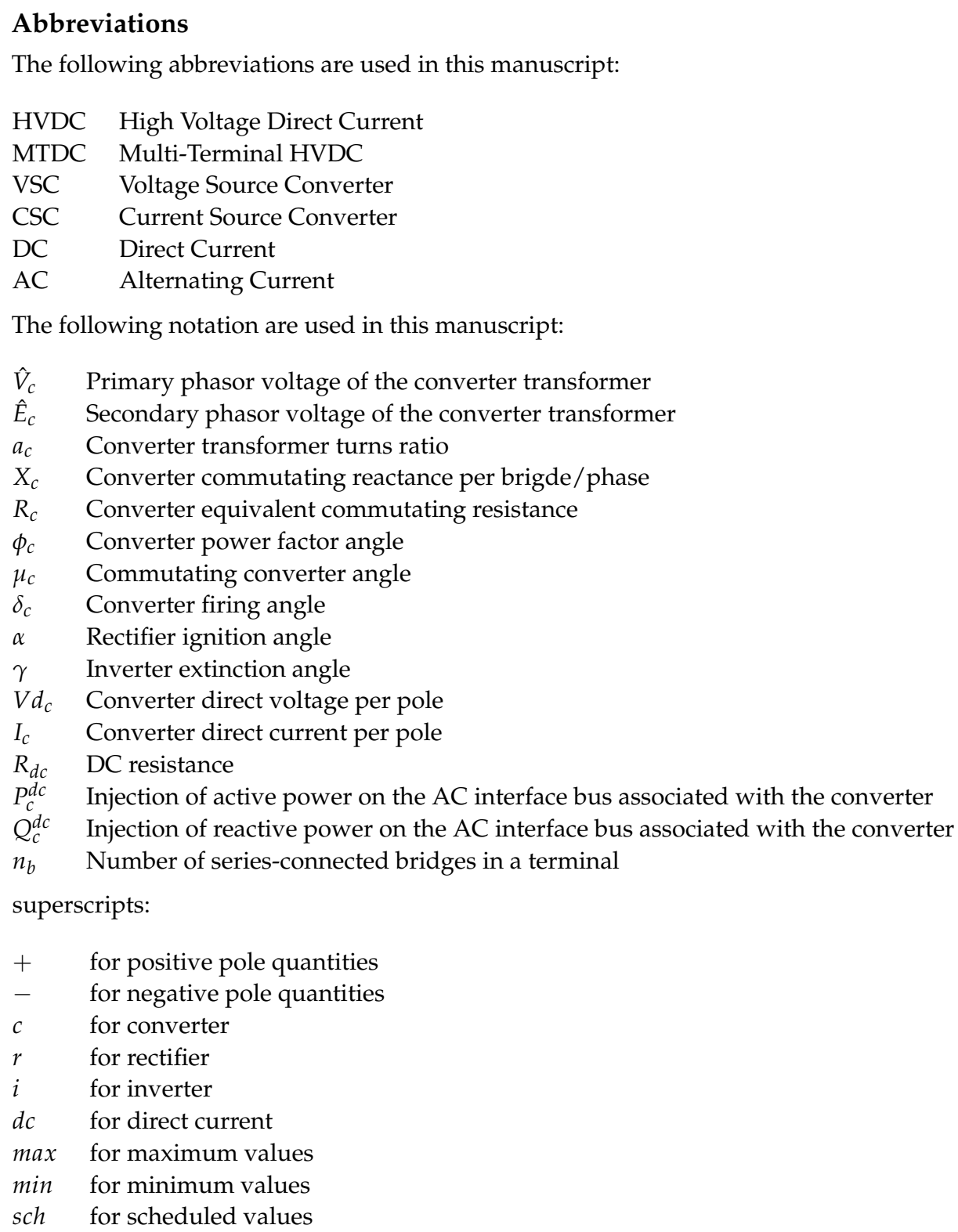

\section{References}

1. Arrillaga, J.A.; Harker, B. Computer Modelling of Electrical Power Systems; John Wiley \& Sons, Inc.: Hoboken, NJ, USA, 1983.

2. Stott, B. Review of load-flow calculation methods. Proc. IEEE 1974, 62, 916-929. [CrossRef]

3. Long, W.; Nilsson, S. HVDC transmission: Yesterday and today. Power Energy Mag. IEEE 2007, 5, 22-31. [CrossRef]

4. Bahrman, M.; Johnson, B. The ABCs of HVDC transmission technologies. IEEE Power Energy Mag. 2007, 2, 32-44. [CrossRef]

5. Henderson, M.; Gagnon, J.; Bertagnolli, D.; Hosie, B.; DeShazo, G.L.; Silverstein, B. Building a plan for HVDC. Power Energy Mag. IEEE 2007, 5, 52-60. [CrossRef]

6. De Sousa Oliveira, P.; de Oliveira, M.T.B.; Oliveira, E.; Conceição, L.R.; Marcato, A.L.M.; Junqueira, G.S.; de Alencar Junior, C.A.V. Maintenance Schedule Optimization Applied to Large Hydroelectric Plants: Towards a Methodology Encompassing Regulatory Aspects. IEEE Access 2021, 9, 29883-29894. [CrossRef]

7. Passos Filho, J.A.; Martins, N.; Falcao, D.M. Identifying Power Flow Control Infeasibilities in Large-Scale Power System Models. IEEE Trans. Power Syst. 2009, 24, 86-95. [CrossRef]

8. Passos Filho, J.A.; da Costa, V.M.; de Oliveira, M.L.; Gomes Junior, S.G. Modeling of ITAIPU's HVDC for SteadyState Assessment. In Proceedings of the IX Symposium of Specialists in Electric Operational and Expansion Planning, Rio de Janeiro, Brazil, 23-27 May 2004.

9. Reeve, J.; Fahny, G.; Stott, B. Versatile load flow method for multiterminal HVDC systems. IEEE Trans. Power Appar. Syst. 1977, 96, 925-933. [CrossRef]

10. Smed, T.; Andersson, G.; Sheble, G.; Grigsby, L. A new approach to AC/DC power flow. Power Syst. IEEE Trans. 1991, 6, 1238-1244. [CrossRef] 
11. Osaloni, O.; Radman, G. Integrated AC/DC systems power flow solution using Newton-Raphson and Broyden approaches. In Proceedings of the Thirty-Seventh Southeastern Symposium on System Theory, 2005. SSST '05., Tuskegee, AL, USA, 20-22 March 2005; pp. 225-229. [CrossRef]

12. Taha, I.B.; Ghoneim, S.; Ashmawy, M.G. Hybrid AC-DC System Power Flow Calculations Based on Modified Newton-Raphson Method. Methods 2017, 4, 10.

13. Li, Z.; He, Y.; Zhang, T.Q.; Zhang, X.P. Universal Power Flow Algorithm for Bipolar Multi-Terminal VSC-HVDC. Energies 2020, 13, 1053. [CrossRef]

14. Narayanan, K.N.; Mitra, P. A comparative study of a sequential and simultaneous AC-DC power flow algorithms for a multi-terminal VSC-HVDC system. In Proceedings of the 2013 IEEE Innovative Smart Grid Technologies-Asia (ISGT Asia), Bangalore, India, 10-13 November 2013; pp. 1-6. [CrossRef]

15. Liu, C.; Bose, A.; Hou, Y. Discussion of the solvability of HVDC systems power flow with a sequential method. Electr. Power Syst. Res. 2012, 92, 155-161. [CrossRef]

16. Liu, C.; Zhang, B.; Hou, Y.; Wu, F.F.; Liu, Y. An Improved Approach for AC-DC Power Flow Calculation With Multi-Infeed DC Systems. IEEE Trans. Power Syst. 2011, 26, 862-869. [CrossRef]

17. Chen, Z.; Chen, H.; Zhuang, M.; Bu, S. Model, Characterization, and Analysis of Steady-State Security Region in AC/DC Power System with a Large Amount of Renewable Energy. Energies 2017, 10, 1181. [CrossRef]

18. Hwang, S.; Song, S.; Jang, G.; Yoon, M. An Operation Strategy of the Hybrid Multi-Terminal HVDC for Contingency. Energies 2019, 12, 2042. [CrossRef]

19. Kaya, F.E. Newton-Raphson Based Load Flow Analysis of AC/DC Distribution Systems with Distributed Generation. Ph.D. Thesis, Middle East Technical University, Ankara, Turkey, 2019.

20. Kundur, P.; Balu, N.J.; Lauby, M.G. Power System Stability and Control; McGraw-Hill: New York, NY, USA, 1994 ; Volume 7.

21. Ping, W. Modelagem de Elos CCAT. Master's Thesis, COPPE/UFRJ, Rio de Janeiro, RJ, Brazil, 1985.

22. Fudeh, H.; Ong, C. A simple and efficient AC-DC load-flow method for multiterminal DC systems. IEEE Trans. Power Appar. Syst. 1981, PAS-100, 4389-4396. [CrossRef] 